\title{
Definições de clareira natural e suas implicações no estudo da dinâmica sucessional em florestas
}

\author{
Renato Soares Armelin ${ }^{1}$ \\ Waldir Mantovani²
}

\begin{abstract}
RESUMO
Clareiras naturais são essenciais à regeneração de florestas tropicais. Diferentes definições de clareira são utilizadas em trabalhos nestas florestas, dificultando uma análise comparativa de seus resultados. Procurou-se comparar duas destas definições com o intuito de verificar se levariam a diferentes resultados florísticos e estruturais. Uma delas baseia-se na abertura no dossel, enquanto a outra na abertura ao nível do solo. Cinco clareiras naturais tiveram sua vegetação de borda estudada. Foram encontradas florística e estrutura da vegetação semelhantes para as duas definições aplicadas. Tais resultados foram creditados principalmente à estrutura heterogênea da mata, que torna seu dossel altamente permeável à luz solar, o que parece minimizar o gradiente microclimático, relativo à incidência de luz, que se esperaria encontrar entre as áreas amostradas segundo as diferentes definições.

Palavras-chave: definições de clareiras naturais, regeneração da Floresta Ombrófila, fitossociologia.

ABSTRACT

Natural gaps are essential to tropical rain forest regeneration. Different gap definitions are used in studies of tropical rain forests, which makes it difficult to compare results. We compared two definitions to find out if they would lead to different floristic and structural results. One definition is based on the canopy opening, while the other on the open area at ground level. Definitions were applied in five gaps, where edge vegetation was studied. Results were not significantly different, and were credited to the irregular structure of the forest what makes its canopy higly permeable to sun light. This condition seems to minimize the microclimate gradient, related to sun light, expected between the two definition áreas sampled.
\end{abstract}

Keywords: definitions of natural gaps, Ombrophylous forest regeneration, phytosociology.

\section{INTRODUÇÃO}

As clareiras naturais são consideradas as principais responsáveis pela regeneração de florestas tropicais e parecem contribuir para a diversidade florística das mesmas (Brokaw, 1982; Denslow \& Hartshorn, 1994; Tabarelli, 1994). Isto está relacionado às condições ambientais especiais que as mesmas apresentam, principalmente no que diz respeito à maior intensidade luminosa (Brokaw, 1982). Segundo Denslow \& Hartshorn (1994), estudando em La Selva, Costa Rica, aproximadamente $75 \%$ das espécies de árvores do dossel são dependentes de clareiras para se estabelecer, já que precisam de suas condições ambientais em, ao menos, um dos estádios de seu ciclo de vida. Segundo Brokaw (1982), as grandes clareiras são responsáveis pela permanência das espécies tipicamente pioneiras, heliófitas, no interior das florestas, ampliando sua diversidade florística. As espécies que dependem de clareiras para

${ }^{1}$ aluno de graduação, bolsista PIBIC/CNPq

${ }^{2}$ Departamento de Ecologia, Instituto de Biociências, USP. Rua do Matão, travessa 14, no 321. Cep 05508-900. Cidade Universitária, São Paulo, SP.

Endereço para correspondência: Renato Soares Armelin, R. Nova York, 609 - apto. 154 . Broadway. CEP 045060-001, São Paulo, SP. Tel: (11) 5090-5203. e-mail: rearmelin@ hotmail.com 
germinar apresentam um padrão de dispersão sazonal que precede à época de maior ocorrência de clareiras naturais que, no caso de Barro Colorado, coincide com a estação chuvosa.

Diversos trabalhos foram publicados abordando diferentes aspectos das clareiras naturais, entre eles os de Runkle (1981), Brokaw (1982) e Denslow \& Hartshorn (1994) que divergem entre si quanto aos critérios empregados. A própria definição de clareira natural feita por cada um destes autores é diferente e, por conseqüência, dificulta a comparação dos seus resultados.

Utilizando as diferentes definições de clareira empregadas por diferentes autores, van der Meer et al. (1994) fizeram um estudo comparativo, no qual avaliaram as implicações nos resultados obtidos. Concluíram que as diferentes definições levaram a resultados diversos no estudo da dinâmica das clareiras. Os autores também observaram que estas definições nem sempre correspondiam às expectativas de produzir resultados precisos, já que nenhuma delas cobria todos os fatores que foram identificados como característicos de clareiras. Tabarelli (1994) concluiu que as características estruturais das clareiras determinam parte do padrão de colonização e da composição de espécies encontradas nas mesmas, e que comunidades colonizadoras não se distribuem aleatoriamente, já que as clareiras pequenas apresentam maior diversidade de espécies e densidade de indivíduos do que as grandes. Em La Selva, Brandani et al. (1988) observaram que diferentes áreas de uma mesma clareira eram floristicamente mais semelhantes em diferentes clareiras do que em diferentes áreas de uma mesma clareira.

As diferentes definições de clareiras naturais parecem produzir resultados diferentes em pesquisas desenvolvidas em florestas tropicais e não têm conseguido incorporar as características ambientais distintas que se observa nas clareiras, como luminosidade, umidade e temperatura. São necessários estudos que indiquem uma definição a ser utilizada de forma mais consensual, que represente mais fielmente as características ambientais associadas às clareiras.

Os objetivos deste trabalho foram: identificar clareiras naturais usando diferentes definições; fazer um levantamento da vegetação relacionada a elas e comparar as diferentes definições de clareiras naturais, tendo por base os resultados obtidos da aplicação de cada uma destas definiçõos.

\section{MATERIAIS E MÉTODOS Local de estudo}

O trabalho foi desenvolvido na reserva florestal da Cidade Universitária Armando de Salles Oliveira (C.U.A.S.O), no bairro do Butantã, São Paulo, S.P., próxima às coordenadas geográficas $46^{\circ} 43^{\circ} \mathrm{N}$ e $23^{\circ} 33^{\prime} \mathrm{S}$. O clima regional é temperado chuvoso, sem estação seca definida, com a temperatura média anual de $19,2^{\circ} \mathrm{C}$ e precipitação de $1207 \mathrm{~mm}$ e umidade relativa do ar em torno de $80 \%$. Está situada no vale de um riacho que se estende no sentido Sul-Norte a, aproximadamente, $795 \mathrm{~m}$ de altitude. A reserva situa-se em uma depressão de terreno, com um desnível de aproximadamente $30 \mathrm{~m}$ entre as partes mais alta e mais baixa (Rossi, 1994).

A mata ocupa uma área de $102.100 \mathrm{~m}^{2} \mathrm{e}$ é um remanescente da floresta que cobria a região. Esta vegetação, segundo a Fundação Instituto Brasileiro de Geografia e Estatística - I.B.G.E., é do tipo Floresta Ombrófila Densa (Veloso et al. 1991). No entanto, a área também é tida como ecotonal, com predominância de Floresta Ombrófila Densa, mas com espécies da Floresta Estacional Semidecidual do interior do estado (Aragaki \& Mantovani, 1998). A mata da reserva não tem uma estratificação nítida, já que, por causa da topografia do local, as copas das árvores não apresentam uma distribuição contínua (Rossi, 1994) e, também, porque apresenta trechos em diferentes estádios de sucessão. As bordas das clareiras eram irregulares e 
possuíam vários estratos de vegetação pouco densos e pouco definidos.

\section{Análise de clareiras naturais}

Duas definições de clareiras naturais, propostas por Brokaw (1982): “A clareira é uma abertura no dossel que se estende verticalmente para o solo, através de todos os níveis da vegetação, devendo ser definida a uma altura média de 2 metros acima do solo", e por Runkle (1981): "A clareira é uma área do solo, sob a abertura do dossel, delimitada pelas bases das árvores de dossel que circundam a abertura do mesmo", foram modificadas e aplicadas (figura 1), como descritas abaixo, sendo os resultados comparados.

As modificações feitas dizem respeito apenas à forma de medir a área das clareiras.
Os autores citados anteriormente desenvolveram metodologia própria para fazer esta medição, ambas baseadas em polígonos, enquanto neste trabalho utilizou-se a fórmula da elipse (Spiegel, 1992).

As clareiras definidas de acordo com Brokaw ou Runkle serão chamadas, ao longo deste texto, de clareiras "tipo Brokaw" ou "tipo Runkle”, respectivamente.

Foram feitas 5 repetições, procurando amostrar clareiras de aproximadamente mesmo tamanho e idade, em trecho de mata com estrutura e idade semelhante. As idades das clareiras foram inferidas com base no grau de regeneração da vegetação interna a elas. Todas as clareiras amostradas, embora de tamanhos variados, foram consideradas de pequeno porte, de acordo com os critérios usados por Brokaw (1982), Denslow \& Hartshorn (1994) e por Tabarelli (1994) (tabela 1).
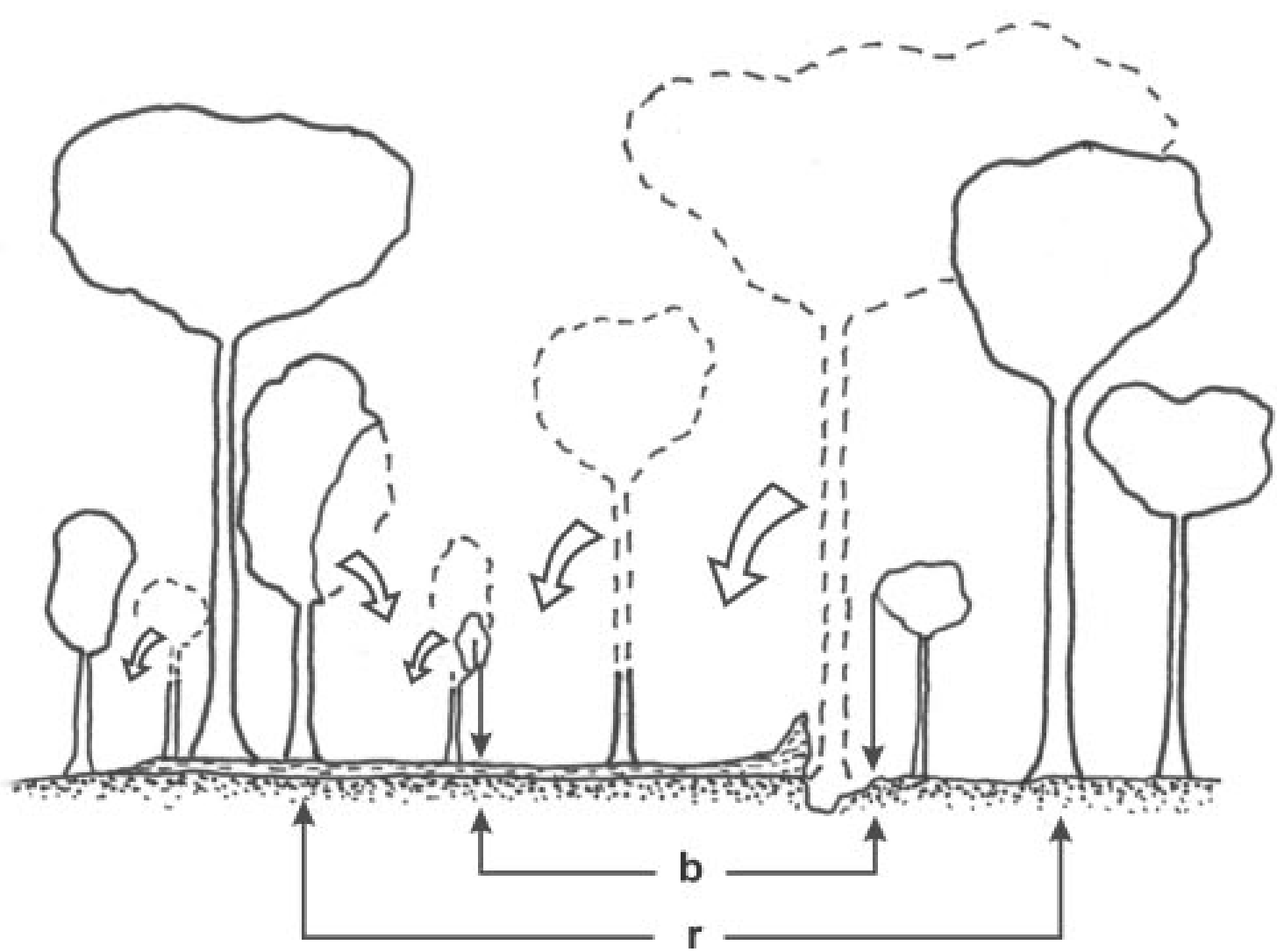

Figura 1. Esquema de clareira natural para a qual foram aplicadas as duas definições estudadas. As linhas contínuas representam árvores ou partes de árvores que permaneceram quando da formação da clareira e as linhas pontilhadas representam árvores ou partes de árvores que caíram ou foram danificadas quando da formação da clareira. $b=$ clareira segundo Brokaw e r = clareira segundo Runkle (adaptado de van der Meer et al. 1994) 
Tabela 1. Quadro resumo das características das clareiras estudadas. $\mathrm{CL}=$ clareira, $\mathrm{O}=$ oeste e $\mathrm{L}=$ leste. Plantas baixas $=$ plantas de altura inferior a $3 \mathrm{~m}$.

\begin{tabular}{|c|c|c|c|c|c|c|c|}
\hline $\mathrm{Cl}$ & $\begin{array}{c}\text { Área } \\
\text { Runkle } \\
\left(\mathrm{m}^{2}\right)\end{array}$ & $\begin{array}{c}\text { Área } \\
\text { Brokw } \\
\left(\mathrm{m}^{2}\right) \\
\end{array}$ & $\begin{array}{c}\text { Idade } \\
\text { sugerida }\end{array}$ & $\begin{array}{l}\text { Agente } \\
\text { formador }\end{array}$ & Centro da clareira & Fisionomia da borda & $\begin{array}{c}\text { Relevo do } \\
\text { terreno }\end{array}$ \\
\hline 1 & 14,50 & 3,62 & 7 meses & $\begin{array}{l}\text { Morte de uma } \\
\text { árvore em pé. }\end{array}$ & $\begin{array}{l}\text { Rebrotas de lianas, } \\
\text { vegetação rarefeita, solo } \\
\text { exposto. }\end{array}$ & $\begin{array}{c}\text { Estratificada, pouco } \\
\text { densa, com muitas } \\
\text { frestas e plantas } \\
\text { baixas. }\end{array}$ & $\begin{array}{l}\text { Declive } \\
\text { acentuado } \\
\text { de } \mathrm{O} \rightarrow \mathrm{L}\end{array}$ \\
\hline 2 & 14,38 & 5,26 & 6 meses & $\begin{array}{l}\text { Queda do } \\
\text { tronco de } 1 \\
\text { árvore. }\end{array}$ & $\begin{array}{l}\text { Tomado pelo tronco, } \\
\text { poucos espaço e } \\
\text { serrapilheira. }\end{array}$ & $\begin{array}{l}\text { Estratificada e } \\
\text { relativamente densa, } \\
\text { com plantas baixas. }\end{array}$ & Plano \\
\hline 3 & 16,27 & 8,13 & 10 meses & $\begin{array}{l}\text { Queda dos } \\
\text { troncos de } 3 \\
\text { árvores. }\end{array}$ & $\begin{array}{c}\text { Restos das copas das } \\
\text { árvores caídas, com lianas } \\
\text { em rebrota. }\end{array}$ & $\begin{array}{l}\text { Borda alta, densa, } \\
\text { pouco estratificada e } \\
\text { com plantas baixas. }\end{array}$ & Plano \\
\hline 4 & 25,51 & 9,60 & 11 meses & $\begin{array}{c}\text { Queda de } 3 \\
\text { galhos e morte } \\
\text { de } 2 \text { árvores } \\
\text { (em pé). }\end{array}$ & $\begin{array}{c}\text { Restos dos galhos caídos e } \\
\text { lianas. Plantas com mais } \\
\text { de } 1,5 \mathrm{~m} .\end{array}$ & $\begin{array}{c}\text { Estratificada, com } \\
\text { muitas frestas e } \\
\text { poucas plantas baixas. }\end{array}$ & $\begin{array}{l}\text { Declive } \\
\text { acentuado } \\
\text { de } \mathrm{O} \rightarrow \mathrm{L}\end{array}$ \\
\hline 5 & 10,40 & 5,89 & 8 meses & $\begin{array}{l}\text { Queda de } 1 \\
\text { galho. }\end{array}$ & $\begin{array}{c}\text { Restos do galho caído e } \\
\text { lianas secas. }\end{array}$ & $\begin{array}{l}\text { Estratificada e densa, } \\
\text { com plantas baixas. }\end{array}$ & Plano \\
\hline
\end{tabular}

Análise da estrutura da vegetação e da regeneração envolvendo clareiras naturais

Estabeleceram-se 15 parcelas de $0,5 \mathrm{x}$ $1 \mathrm{~m}$ em cada faixa de vegetação de borda das clareiras, que foram identificadas de acordo com as definições analisadas. Nas clareiras 1 e 2 foram estabelecidas três parcelas para cada definição, na clareira 3 estabeleceu-se uma parcela para cada definição e nas clareiras 4 e 5 foram estabelecidas quatro parcelas para cada definição; posicionadas com seus lados maiores paralelos aos limites das copas das árvores, para ambas as definições.

A flora obtida foi analisada para determinar os diversos componentes da vegetação associada às clareiras. Mediramse as alturas das plantas com alturas iguais ou superiores a $15 \mathrm{~cm}$, que seriam representativas das mudanças estabelecidas pelas clareiras recém abertas, evitando-se amostrar plântulas. O material foi identificado através de chave de identificação proposta por Rossi (1994) e as espécies que não constavam na chave foram identificadas por comparação com materiais de herbário depositados no Laboratório de Fitossociologia do
Departamento de Ecologia e no Laboratório de Sistemática do Departamento de Botânica do Instituto de Biociências da Universidade de São Paulo.

Os descritores da estrutura da vegetação calculados foram: densidade, dominância e freqüência absolutas, de acordo com MuellerDombois \& Ellenberg (1974). A dominância foi determinada com base na altura das plantas. Foram utilizados testes de variância que indicassem o esforço amostral necessário para representar a estrutura da vegetação (Zar, 1996). Foram construídas curvas de coletores para análise da suficiência amostral florística (Mueller-Dombois \& Ellenberg 1974).

Para discussão dos resultados, as espécies amostradas foram classificadas em diferentes grupos (tabela 2), três deles baseados na tolerância à luz solar: heliófitas, cujo ciclo de vida é exclusivamente heliófilo, tolerante à sombra, que apresenta pelo menos um estádio ciófilo em seu ciclo de vida e ciófita, cujo ciclo de vida é exclusivamente ciófilo. As espécies também foram classificadas de acordo com o estrato e local da mata onde predominam: dossel, sub-bosque, herbáceo ou borda, e quanto à sua forma de vida predominante: 


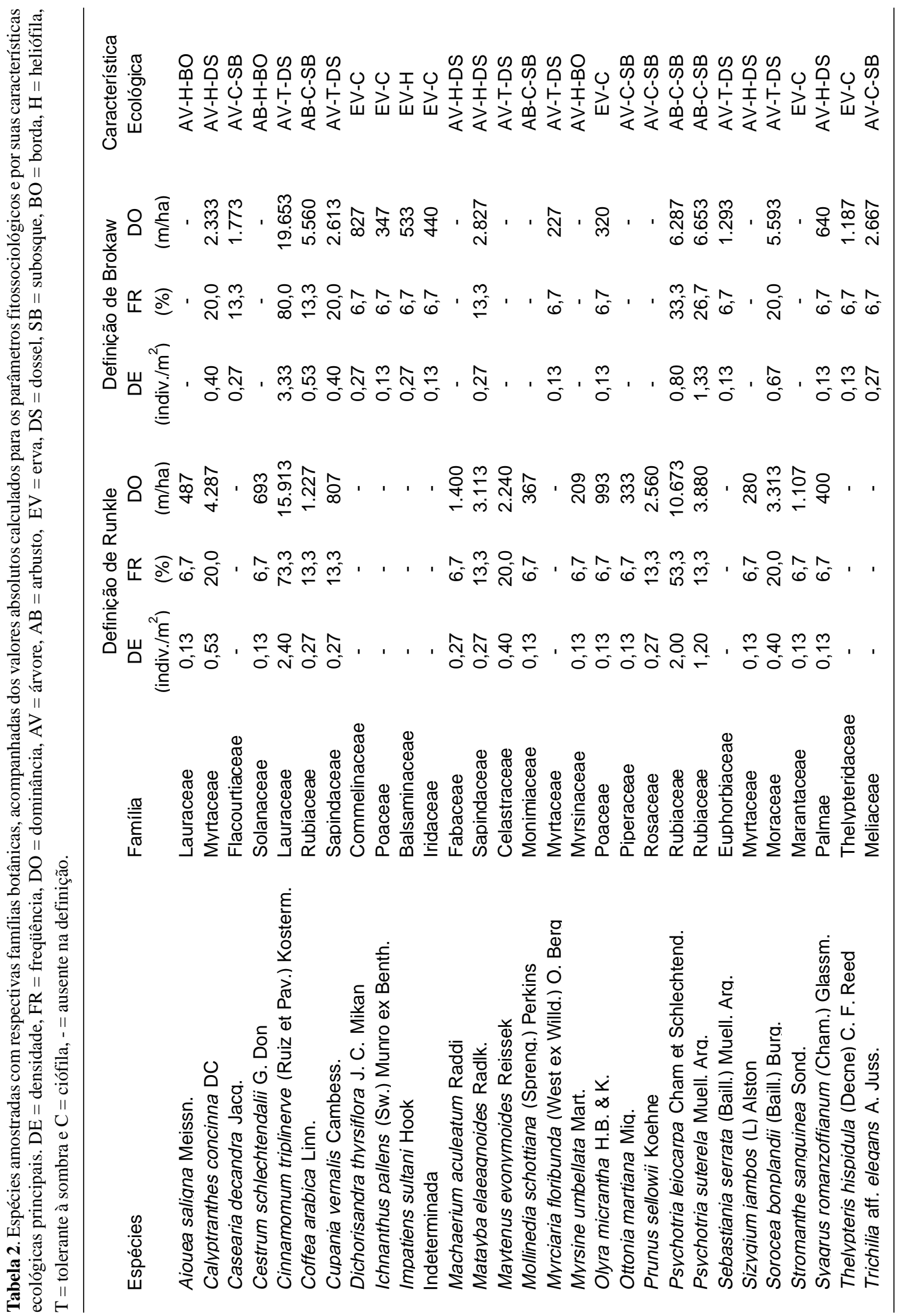


árvore, arbusto ou erva, conforme Rossi (1994), Klein \& Sleumer (1984) e observações de campo.

\section{RESULTADOS}

Os valores de variância obtidos para cada uma das definições estudadas: $\mathrm{S}^{2} \mathrm{~B}=3,55 \mathrm{e}$ $S^{2} R=10,80$ foram baixos, indicando que o esforço amostral foi suficiente para que os dados obtidos fossem representativos da estrutura da vegetação em estudo. Tais valores também mostram que dentro da definição de Runkle, a vegetação apresentou uma estrutura mais diversificada, já que para o mesmo esforço amostral utilizado para a definição de Brokaw, sua variância foi maior. As curvas de coletores (figura 2) tenderam à estabilidade, indicando que as espécies mais comuns na vegetação, responsáveis pela fisionomia, foram suficientemente amostradas.

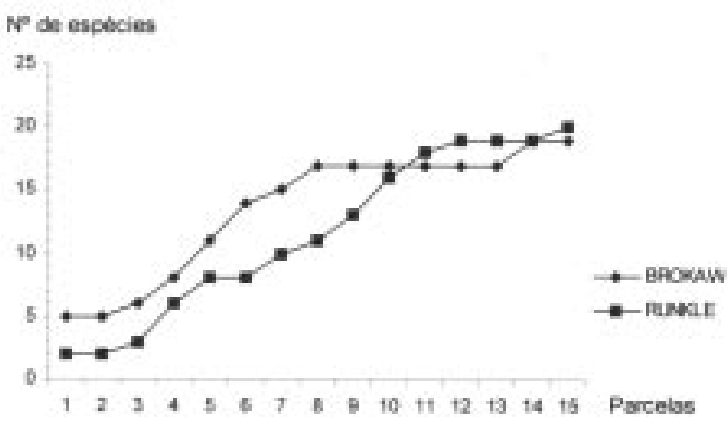

Figura 2. Curvas de coletores referentes à vegetação de bordas das clareiras, amostrada segundo as definições estudadas.

\section{Flora associada às clareiras}

Foram amostradas 144 plantas de 29 espécies pertencentes a 22 famílias botânicas, sendo que 73 destas foram coletadas de acordo com clareira tipo Brokaw e 71 de acordo com clareira tipo Runkle. As espécies mais abundantes no levantamento florístico foram: Cinnamomum triplinerve, com 43 indivíduos, Psychotria suterella com 21 indivíduos, e Psychotria leiocarpa, com 19 indivíduos. As famílias mais ricas foram Rubiaceae e Myrtaceae, com 3 espécies cada.
Das 29 espécies amostradas, 11 são componentes do dossel da mata, 3 são típicas de bordas e 15 são de submata, incluindo-se aí as herbáceas. Das 17 árvores encontradas, as de maiores densidades, freqüências e dominâncias foram $C$. triplinerve, Sorocea bonplandii e Cupania vernalis, tolerantes à sombra de dossel, e Calyptranthes concinna, heliófita de dossel.

Do componente arbustivo foram identificadas 5 espécies, uma típica de borda e 4 típicas de submata, ressaltando-se $P$. suterela e $P$. leiocarpa, ciófitas de subosque. O estrato herbáceo foi representado por 7 espécies, 6 ciófitas (incluindo Thelypteris hispidula, uma pteridófita) e 1 heliófita, de áreas mais abertas da mata, sendo que nenhuma destas obteve valores significativos para os descritores calculados. Ao todo foram encontradas 9 espécies heliófitas (31\%), 6 tolerantes à sombra $(21 \%)$ e 14 ciófitas $(48 \%)$ (tabela 2).

\section{Comparação das diferentes definições}

Nas clareiras tipo Brokaw, foram encontradas 19 espécies (66\% do total) e, nas clareiras tipo Runkle, 20 espécies (69\% do total). Tratam-se de valores muito próximos, sendo comuns a ambas as definições 10 espécies (34\% do total). As espécies mais abundantes foram amostradas nos dois tipos de clareiras. Os resultados dos descritores fitossociológicos (tabela 2) confirmam a predominância de $C$. triplinerve, $P$. suterela e $P$. leiocarpa, sendo que as duas primeiras apresentam valores maiores dentro da clareira tipo Brokaw e P. leiocarpa quando dentro da clareira tipo Runkle. C. concinna apresentou comportamento semelhante ao de $P$. leiocarpa, já $C$. vernalis e $S$. bonplandii mostraram valores mais significativos na clareira tipo Brokaw. Estas seis espécies compreendem $72 \%$ dos indivíduos amostrados.

Empregando-se a metodologia proposta por Brokaw, obteve-se no levantamento florístico 8 plantas heliófilas (38\% das heliófitas) estando estas distribuídas entre 4 
espécies; 35 plantas tolerantes à sombra $(57 \%$ das tolerantes à sombra) distribuídos por 5 espécies e 30 plantas ciófilas (48\% das ciófitas). Quando utilizada a metodologia proposta por Runkle, obtiveram-se 13 plantas heliófilas (62\% das heliófitas) distribuídas em 8 espécies; 26 plantas tolerantes à sombra (43\% das tolerantes à sombra) e 32 plantas ciófilas (52\% das ciófitas).

Entre as 9 espécies heliófitas, apenas Impatiens sultani predominou na definição baseada na abertura do dossel, sendo exclusiva à clareira tipo Brokaw, com apenas 2 plantas amostradas; 5 destas espécies foram encontradas exclusivamente na clareira tipo Runkle, 4 delas com apenas 1 planta e a quinta com 2 plantas amostradas e outras 3 foram amostradas em proporções equivalentes para os dois tipos de clareiras. Em relação às espécies tolerantes à sombra, a clareira tipo Brokaw apresentou 2 espécies exclusivas, ambas com apenas 1 planta e a clareira tipo Runkle 1 espécie exclusiva, com 3 plantas amostradas. Das 3 espécies comuns aos dois tipos, $C$. triplinerve e $S$. bonplandii predominam no de Brokaw, enquanto $C$. vernalis não mostrou preferência. Quanto às espécies ciófitas, 6 mostraram-se exclusivas à clareira tipo Brokaw e 4 à clareira tipo Runkle, nenhuma delas representada por mais de 2 plantas. Outras 4 espécies foram comuns a ambos os tipos, sendo que $P$. leiocarpa predominou no de Runkle e Coffea arabica no de Brokaw. As 2 restantes mostraram valores equivalentes para ambas as definições.

No que diz respeito às árvores do dossel, três espécies foram exclusivas à clareira tipo Runkle, com três, duas e uma planta; seis eram comuns a ambas as definições e duas eram exclusivas à clareira tipo Brokaw, com uma planta. As espécies de sub-bosque dividiramse em quatro espécies de árvores, duas exclusivas à clareira tipo Brokaw e duas à clareira tipo Runkle, com até duas plantas cada; e quatro espécies de arbustos, uma exclusiva, com uma planta, e uma predominante na clareira tipo Runkle; uma predominando na clareira tipo Brokaw e a quarta sem demonstrar preferência significativa por qualquer dos tipos. As espécies de borda de mata dividiram-se em duas árvores e um arbusto, todos heliófilos e exclusivos à clareira tipo Runkle, representadas por uma planta. O estrato herbáceo foi caracterizado por cinco espécies exclusivas à clareira tipo Brokaw, incluindo a única erva heliófila encontrada - I. sultani; uma exclusiva à clareira tipo Runkle e uma comum a ambas, com até duas plantas (tabela 3).

\section{Descritores fitossociológicos}

Os mais altos valores de densidade foram encontrados para $C$. triplinerve, $P$. suterela $\mathrm{e}$ $P$. leiocarpa, para ambos os tipos de clareiras, enquanto para frequiências absolutas sobressaíram-se $C$. concinna e $C$. vernalis, com valores próximos aos de $P$. suterela. $C$. concinna é mais freqüente que $P$. suterela na clareira tipo Runkle. No entanto, P. suterela apresentou mais do que o dobro de indivíduos do que $C$. concinna e $C$. vernalis, em ambos os tipos de clareiras. Em dominância ressaltase $C$. concinna, com valor superior ao de $P$. suterela, dentro da clareira tipo Runkle.

\section{DISCUSSÃO}

As clareiras naturais têm fisionomia muito irregular, sendo que a borda entre a abertura das mesmas e a vegetação que as circunda poucas vezes é bem definida (van der Meer et al, 1994), dificultando a medida das

Tabela 3. Quadro resumo da flora associada às clareiras, com base nas características das espécies amostradas exclusivamente segundo Runkle ou segundo Brokaw. $\mathrm{AV}=$ árvore, $\mathrm{AB}=$ arbusto, $\mathrm{EV}=$ erva, $\mathrm{DS}=$ dossel, $\mathrm{SB}=$ subosque, $\mathrm{BO}=\mathrm{borda}$, $\mathrm{H}=$ heliófila, $\mathrm{T}=$ tolerante à sombra e $\mathrm{C}=$ ciófila

\begin{tabular}{c|cccccccccc}
\hline Clareira & Espécies & H & T & C & BO & DS & SB & AV & AB & EV \\
\hline Runkle & 10 & 5 & 1 & 4 & 3 & 3 & 3 & 7 & 2 & 1 \\
Brokaw & 9 & 1 & 2 & 6 & 0 & 2 & 2 & 4 & 0 & 5 \\
\hline
\end{tabular}

Rodriguésia 52(81): 5-15. 2001 
clareiras estudadas. A utilização da fórmula da elipse e a tomada de dois diâmetros de borda não forneceram além de uma aproximação do tamanho real das mesmas.

A precisão de medida da definição de Brokaw é baixa (van der Meer et al. 1994), pois depende de uma projeção vertical da abertura do dossel e é baseada em poucos pontos de medidas de borda, critérios que não expressam a irregularidade da abertura no dossel, enquanto a definição de Runkle é precisa quando identificadas as árvores de borda. Os resultados obtidos na reserva da C.U.A.S.O. não confirmaram os de van der Meer et al. (1994) em Floresta Ombrófila Densa na Guiana Francesa, para a definição de Runkle, porque, mesmo quando foram facilmente identificadas as árvores componentes da borda, estas não estavam dispostas de forma regular.

Para estimar a área das clareiras, Brokaw baseou-se em um centro projetado e 8 medidas de borda, eqüidistantes, formando um polígono; enquanto Runkle utilizou-se também de um centro projetado e sua distância para cada uma das árvores formadoras da borda, também formando um polígono. Isto não pareceu interferir nos resultados obtidos, pois o interesse foi o da análise comparativa dos mesmos. De qualquer forma, trocaram-se duas fórmulas originais e parecidas, baseadas em polígonos, por uma única, da elipse.

Estudando clareiras quanto à abertura no dossel e quanto à abertura ao nível do chão, van der Meer et al. (1994) concluíram que a definição de Runkle era a melhor para se trabalhar. Seus resultados mostraram que as clareiras medidas a partir da abertura no dossel eram sempre menores do que as medidas ao nível do solo, já que as copas das árvores que compõem a borda quase sempre se projetam para dentro da abertura da clareira. Os resultados obtidos na reserva da C.U.A.S.O. comprovaram esta relação de tamanho das clareiras para as diferentes definições (tabela 1).

Uma dificuldade importante na determinação do tamanho das clareiras foi a presença, em geral, de uma planta com altura superior a dois metros localizada dentro do que seria a abertura original da mesma. Segundo a definição proposta por Brokaw, esta planta deveria ser considerada como borda, delimitando a abertura da clareira. Foi o que aconteceu na clareira de número três, onde a planta também foi considerada borda para a definição de Runkle. São necessários novos trabalhos para determinar se o sombreamento que estas plantas isoladas causam próximo de si é realmente significativo, pois a clareira continua aberta ao seu redor e a quantidade de luz no interior da mesma pareceu ser pouco afetada pela sua presença. Van der Meer et al. (1994) consideraram a definição de Brokaw subjetiva e pouco acurada, em razão da dificuldade de aplicá-la quando eram encontrados fragmentos isolados de vegetação com alturas superiores a dois metros dentro da área da clareira.

Em razão das dificuldades e distorções causadas por definições de clareiras baseadas em alturas e distâncias, Whitmore et al. (1993) sugeriram uma definição de clareira dada por fatores microclimáticos, os verdadeiros determinantes do recrutamento das espécies, porque não é esperado encontrar uma variação abrupta nestes fatores quando se ultrapassa uma fronteira determinada geometricamente entre duas áreas vizinhas, dentro de uma mesma clareira.

Das 29 espécies amostradas, 10 eram comuns a ambos os tipos de clareiras e respondiam por $81 \%$ dos indivíduos amostrados. Quanto às 19 espécies exclusivas, das quais 12 foram amostradas por 1 planta, apenas $M$. evonymoides, árvore de dossel amostrada na definição de Runkle, pode ser considerada significativa na análise fitossociológica. Contudo, devido às suas características ecológicas, sendo tolerante à sombra, e à sua abundância, não indica diferenças significativas nas condições de recrutamento de espécies das diferentes definições estudadas. A composição da flora associada a essas diferentes definições de 
clareiras mostrou-se muito semelhante. $\mathrm{O}$ predomínio foi de $C$. triplinerve, $P$. suterela $\mathrm{e}$ $P$. leiocarpa, que mostraram uma distribuição semelhante em ambos os tipos de clareiras. Outras espécies bem representadas, como $S$. bonplandii e $C$. vernalis, tolerantes à sombra, e especialmente $C$. concinna, heliófila, também não demonstraram preferência significativa por qualquer das definições.

A vegetação mostrou-se um pouco mais rica e densa quando na clareira tipo Runkle, com maior diversidade de árvores e arbustos, tanto no que se refere às espécies de dossel quanto às de subosque. Este padrão de recrutamento pode ter ocorrido pela clareira tipo Runkle analisar uma área com condições ambientais que se assemelham mais às de subosque do que a clareira tipo Brokaw e, como a maioria das espécies amostradas era típica de subosque ou ciófila jovem, seria natural que se desenvolvessem melhor dentro da clareira tipo Runkle. Todavia, são necessários estudos específicos para testar esta hipótese.

Seria de se esperar uma predominância de plantas heliófitas com a aplicação da definição de Brokaw, por esta ser mais interna ao centro da clareira e, assim sendo, mais exposta à luz que chega da abertura no dossel. No entanto, das 9 heliófitas obtidas, 5 foram exclusivas à clareira tipo Runkle e apenas 1 à clareira tipo Brokaw. Quanto às 3 heliófitas comuns às duas definições, nenhuma mostrou valores altos para os descritores fitossociológicos quando na clareira tipo Brokaw. Syagrus romanzoffiana mostrou resultados idênticos para frequiência e densidade e apenas a dominância ligeiramente mais alta quando na definição de Brokaw; $C$. concinna teve valores mais altos nos três parâmetros fitossociológicos quando na clareira tipo Runkle e Matayba elaeagnoides teve valores idênticos de densidade e freqüência para ambas as definições, com uma dominância ligeiramente superior quando na clareira tipo Runkle.

A heterogeneidade das clareiras estudadas (tabela 1) pareceu não ter influenciado significativamente no recrutamento de espécies. Os resultados observados talvez possam ser explicados pela própria estrutura da mata da reserva da C.U.A.S.O., cuja irregularidade deve ter propiciado a formação de várias frestas por onde passava luz solar. Trata-se de um fragmento de mata antropizado, onde existem espécies exógenas que são responsáveis por alterações da fisionomia da vegetação. Algumas espécies são decíduas no inverno, alterando o nível de sombreamento do dossel. Além disso, o baixo porte da mata determina um tamanho pequeno para as clareiras, que têm o tamanho correlacionado à altura das árvores que as formam (Brokaw, 1982), o que diminui o gradiente ambiental dentro das mesmas. Por outro lado, a mata da C.U.A.S.O. é um fragmento pequeno e, portanto, fica mais fácil que propágulos vindos dos arredores da mata, especialmente de espécies heliófitas, possam se instalar nela, já que a distância para a dispersão é menor do que nas outras matas estudadas pelos diferentes autores citados neste trabalho. Os trabalhos de van der Meer et al. (1994) e de Brandani et al. (1988) foram realizados em matas não antropizadas, de porte mais elevado.

A coleta dos dados foi feita nos meses de julho e agosto, no inverno, com influência de sazonalidade na oferta de propágulos disponíveis para colonizar as clareiras. Épocas de chuva e ventos fortes favorecem a formação de clareiras (Brokaw, 1982), que no caso da reserva da C.U.A.S.O., coincide com o verão. Seria esperado que as espécies heliófitas concentrassem a dispersão de seus propágulos nessa época, com uma maior oferta de clareiras e maior disponibilidade de sítios próprios para seu desenvolvimento.

A irregularidade das bordas das clareiras formou espaços por onde a radiação solar passava integralmente. Pulsos de radiação solar parecem ser capazes de induzir o desenvolvimento de plantas em áreas cobertas, pois fornecem os mesmos comprimentos de onda que estas receberiam se estivessem em 
uma clareira (Richards, 1996). Tais pulsos de luz solar podem ter sido responsáveis por um incremento de luminosidade na zona delimitada pela definição de Runkle, aumentando o fluxo diário de fótons nesta área e, assim, diminuindo o gradiente de luminosidade entre as zonas das duas definições. Este incremento também ocorreria na zona da definição de Brokaw, mas não seria significativo, pois a luminosidade nesta área já seria suficiente para permitir o padrão de recrutamento que foi observado. Por outro lado, não seria suficiente para tornar-se limite às espécies encontradas no local. Desta forma, o fluxo diário de fótons na zona da definição de Runkle deve ter atingido níveis tais que permitiram um recrutamento de espécies semelhante ao que ocorreu na zona da definição de Brokaw. Caso houvessem condições particulares de recrutamento em cada definição, em especial um maior aporte de luz na área da definição de Brokaw, seria de se esperar que as espécies ciófilas e heliófilas melhor amostradas ( $P$. leiocarpa e $P$. suterella - ciófilas e $C$. concinna - heliófila) se concentrassem nas áreas das definições de Runkle e de Brokaw, respectivamente, o que não aconteceu.

\section{CONCLUSÕES}

As clareiras naturais são formações muito irregulares, onde é difícil aplicar as duas definições propostas, especialmente a de Brokaw. Tais definições, baseadas em medições geométricas, não corresponderam à variação microclimática observada em clareiras e, também, não foram capazes de lidar com toda a irregularidade que tanto a abertura no dossel como as configurações das bordas das clareiras costumam apresentar.

Os resultados obtidos não foram significativamente diferentes, o que pode ter acontecido porque as duas definições não delimitaram zonas microclimáticas significativamente distintas, provavelmente porque a radiação solar vinda de frestas das bordas das clareiras e de aberturas sazonais no dossel da mata devem ter minimizado o gradiente microclimático entre estas duas zonas. Assim sendo, as definições estudadas levaram a resultados semelhantes na mata da reserva da C.U.A.S.O.

As dificuldades e distorções de medidas, comuns às duas definições de clareiras avaliadas neste trabalho, fizeram com que se buscassem novas abordagens para estudar clareiras. A mais interessante, apesar de também apresentar problemas quanto à precisão de suas medidas, é a proposta por Whitmore et al. (1993), que se baseia em parâmetros microclimáticos, que são, na realidade, os responsáveis pela diversidade e distribuição da flora relacionada às clareiras. No entanto, não foi feito nenhum teste desta definição neste trabalho, que permita sugerir que a mesma seja adotada.

\section{AGRADECIMENTOS}

Ao CNPq, pela bolsa de iniciação científica.

\section{REFERÊNCIAS BIBLIOGRÁFICAS}

Aragaki, S. \& Mantovani, W. 1998. Caracterização do clima e da vegetação de remanescente florestal no planalto paulistano (SP). In Simpósio de Ecossistemas Brasileiros. 4. Águas de Lindóia. 1998. Anais. São Paulo, Academia de Ciências do Estado de São Paulo, ACIESP 104 (2): p.25-36.

Brandani, A.; Hartshorn, G. S. \& Orians, G. H. 1988. Internal heterogeneity of gaps and species richness in Costa Rican tropical wet forest. Journal of Tropical Ecology 4: 99-119.

Brokaw, N. V. L. 1982. Treefalls: frequency, time, and consequences. In: E. G. Leight, Jr.; A. S. Rand; D. M. Windsor (eds.). The Ecology of a Tropical Forest: Seasonal Rythms and Long-Term Changes. Smith. Inst. Press, Washington, D.C., U.S.A. p.101-108.

Denslow, J. S. \& Hartshorn, G. S. 1994. Treefall Gap Environments and Forest Dynamic Process. In: L. A. McDade; K. 
S. Bawa; H. A. Hespenheide; G. S. Hartshorn (eds.). LA SELVA - Ecology and Natural History of a Neotropical Rain Forest. The University of Chicago Press, Chicago, U.S.A. p.120 - 128.

Klein, R. M. \& Sleumer, H. O. 1984. Flora Ilustrada Catarinense Flacourtiáceas, $1^{\mathrm{a}}$ parte. Raulino Reitz ed. Herbário Barbosa Rodrigues, Santa Catarina, Brasil. 96p.

Mueller-Dombois, D. \& Ellenberg, H. 1974. Aims and Methods of Vegetation Ecology. New York, Willey and Sons, $517 \mathrm{p}$.

Richards, P. W. 1996. The Tropical Rain Forest: an ecological study. $2^{\text {nd }}$ ed. Cambridge University Press. UK. 575p.

Rossi, L. 1994. Flora Arbóreo-Arbustiva da Mata da Reserva da Cidade Universitária "Armando de Salles Oliveira", São Paulo, Brasil. Boletim do Instituto de Botânica 9: 01-105.

Runkle, J. R. 1981. Gap regeneration in some old-growth forests of the eastern United States. Ecology 62, 4: 1041-1051.

Spiegel, M. R. 1992. Manual de Fórmulas, Métodos e Tabelas de Matemática. $2^{\mathrm{a}}$ edição. São Paulo. Makron Books, 428p.

Tabarelli, M. 1994. Clareiras Naturais e a Dinâmica Sucessional de um Trecho de Floresta na Serra da Cantareira, $S P$. Dissertação (mestrado). Instituto de Biociências - USP. São Paulo, SP. 142p. van Der Meer, P. J.; Bongers, F.; Chatrou, L. \& Riéra, B. 1994. Defining canopy gaps in a tropical rain forest: effects on gap size and turnover time. Acta OEcologica 15 (6): 701-714.

Veloso, H. P.; Rangel Filho, A. L. R.; Lima, J. C. A. 1991. Classificação da Vegetação Brasileira Adaptada a um Sistema Universal. RJ. IBGE; Departamento de Recursos Naturais e Estudos Ambientais. 123p.

Withmore, T. C.; Brown, N. D.; Swaine, M. D.; Kennedy, D.;Goodwin-Bailey \& Gong, W. K. 1993. Use of hemispherical photographs in forest ecology: measurement of gap size and radiation totals in Bornean tropical rain forest. Journal of Tropical Ecology 9: 131-159.

Zar, J. H. 1996. Biostatistical Analysis. $3^{\text {rd }}$ ed. Upper Saddle River, Prentice-Hall. $662 p$. 
